\title{
Reproducibility and Validity of a Self-administered Food Frequency Questionnaire Used in the JACC Study
}

\author{
Chigusa Date, ${ }^{1}$ Mitsuru Fukui, ${ }^{2}$ Akio Yamamoto, ${ }^{3}$ Kenji Wakai, ${ }^{4}$ Azusa Ozeki, ${ }^{5}$ Yutaka Motohashi, \\ Chieko Adachi, ${ }^{7}$ Naoyuki Okamoto, ${ }^{8}$ Michiko Kurosawa, ${ }^{9}$ Yuko Tokudome, ${ }^{10}$ Yoko Kurisu, ${ }^{11}$ \\ Yoshiyuki Watanabe, ${ }^{12}$ Kotaro Ozasa, ${ }^{12}$ Shuichi Nakagawa, ${ }^{13}$ Noritaka Tokui, ${ }^{14}$ Takesumi Yoshimura, ${ }^{15}$ \\ Akiko Tamakoshi, ${ }^{16}$ for the J ACC Study Group.
}

\begin{abstract}
BACKGROUND: A self-administered questionnaire on dietary habits used in the JACC Study contained a 40-item food frequency questionnaire (FFQ). Although more than 110 thousand subjects enrolled in JACC Study and responded to the FFQ, no validation study has been conducted to date.

METHODS: Eighty-five volunteers among the cohort members completed 2 FFQs (FFQs 1\&2) and 12day weighed dietary records (WDR). The interval between the two FFQs was one year. During the one year, the subjects carried out a 3-consecutive-day WDR in each season. We tested the reproducibility by using two FFQs. Also, we tested the validity of the FFQ by using the 12-day WDR as a gold standard.

RESULTS: The intake frequencies of the 2 FFQs often agreed, showing the Spearman correlation coefficients ranging from 0.42 (edible wild plants) to 0.86 (coffee). The Spearman correlation coefficients of the energy and nutrient intakes from FFQ2, and that of the 12-day WDR were 0.20 (energy) to 0.46 (animal protein, potassium). After adjusting the energy intake, the correlation coefficients showed 0.21 (fish fat) to 0.51 (animal fat). When classifying the FFQ2 and WDR by quartiles and examining the degree of agreement between the two methods, we obtained its median $30 \%$.

CONCLUSIONS: The FFQ is suitable to deal with a large group of subjects. However, since the energy and the amount of nutrient intake from this FFQ can not show the overall dietary intake situation, the subjects' dietary intake should be assessed by categories.
\end{abstract}

J Epidemiol 2005; 15:S9-S23.

Key words: food frequency questionnaire, weighed dietary record, validity, reproducibility.

Received September 17, 2004, and accepted December 19, 2004.

The J ACC Study has been supported by Grants-in-Aid for Scientific Research from the Ministry of Education, Science, Sports and Culture of Japan (Monbusho) (No. 61010076, 62010074, 63010074, 1010068, 2151065, 3151064, 4151063, 5151069, 6279102 and 11181101).

1 Department of Nutrition and Food Sc iences, Faculty of Human Environmental Sc iences, Mukogawa Women's University.

2 Laboratory of Statistics, Osaka City University Medic al School.

3 Infectious Disease Research Division, Hyogo Prefectural Institute of Public Health and Environmental Sciences.

4 Aichi Cancer Center Research Institute.

5 Yakumo-cho town office.

6 Akita University School of Medic ine.

Showa University School of Medic ine.

8 Kanagawa CancerCenter.

9 J untendo University Sc hool of Medic ine.

${ }^{10}$ Nagoya Bunri University.

${ }^{11}$ Gifu University Graduate School of Medic ine.

${ }^{12}$ Kyoto Prefectural University of Medic ine Graduate School of Medic al Science.

${ }^{13}$ Nakagawa Clinic (Nephrology and Urology).

${ }^{14}$ Institute of Industrial Ec ologic al Sc iences, University of Occupational and Environmental Health.

${ }^{15}$ Fukuoka Institute of Health and Environmental Sciences.

${ }^{16}$ Nagoya University Graduate School of Medic ine.

Address for correspondence: Chigusa Date, Department of Food Science and Nutrition, Faculty of Human and Environment, Nara Women's University, Kita uoya nishi-machi, Nara 630-8506, Japan. (chigusa @cc.nara-wu.ac.jp) 
"The Japan Collaborative Cohort Study (JACC Study) for Evaluation of Cancer Risk Sponsored by the Ministry of Education, Science, Sports and Culture of Japan (Monbusho)" is a large-scale population-based cohort study which launched in 45 municipalities all over Japan. ${ }^{1}$

Epidemiologic data were collected at baseline (1988-1990) through a self-administered questionnaire with the written informed consent of the respondents, including such demographic information as sex, date of birth, marital status, number of children and medical history. Questions on their dietary habits were also included, such as the bowls of steamed rice they ate daily; the intake frequency of miso (traditional Japanese soybean paste) soup; the amount of its daily consumption in bowls at baseline. There were also questions about the intake frequency concerning 33 items with the use of 5 response categories, and those concerning alcoholic beverages and soft drinks.

In many large-scale population based on nutritional epidemiologic studies for analyzing the relation of nutrient intakes and health outcomes, a self-administered semi-quantitative food frequency questionnaire (SQFFQ) was used. ${ }^{2}$ SQFFQ is composed of a food list and a frequency response section in which subjects are asked to report how often they consumed foods daily. This is the method by which the daily intake of nutrients was calculated by multiplying the intake frequency by the nutrients contained in portion sizes. However, in Japan little attention has been paid so far to the validity of the method of computing the amount of nutrient intake this way ${ }^{3}$. Moreover, although the intake frequency of specific food items or food groups is used to clarify the relation between the frequency and the incidence of diseases, a validation study has not been conducted, based on the actual intake frequency counted from the multiple-day dietary records.

We developed the method of evaluating the frequency and amount of consumed steamed rice, miso soup and beverages, and 33 food items. We tested the reproducibility and validity of frequency response and the method of estimating the amount of nutrients.

\section{METHODS}

\section{Subjects}

From among 24 groups who participated in the JACC Study, we obtained 5 to 10 volunteers from the 15 groups who could conduct the weighed dietary record method, and regarded them as subjects. They came from all over Japan: from prefectures in the north to those in the south such as Hokkaido, Akita, Tokyo, Kanagawa, Yamanashi, Nagano, Aichi, Gifu, Kyoto, Hyogo, and Fukuoka. Except for Kyoto (3 groups) and Aichi and Gifu (2 groups each), there was one group from such prefectures. The participants numbered 89 when the research started. Here are the specific numbers of the subjects and their prefectures: 5, Yakumo Town, Hokkaido; 5, Omori Town, Akita; 5, Samukawa Town, Kanagawa; 10, Higashi-Yamanashi County, Yamanashi; 6, Shirakawa Town, Gifu; 5, Gifu City, Gifu;4, Wachi Town, Kyoto; 7, Wazuka Town, Kyoto; 5, Keihoku Town, Kyoto; 10, Ichinomiya Town, Hyogo; 5, Saikawa Town, Fukuoka. In addition, as occupational groups, 11 from preventive medicine associations in Tokyo; 5 personnel from the Nagoya City government and 5 dietitians from Nagoya City also participated, totaling of 89 subjects.

\section{Research Design}

The research design is outlined in Figure 1. As a method of showing the usual dietary intake level, we adopted the weighed dietary record method (WDR) by which the subjects recorded the dietary intake for 3 consecutive days (week days) every 3 months: spring, summer, autumn and winter. In other words, the subjects did the WDR, totally 12 days a year. Owing to the various stages of preparation for the research, the first group started in the summer of 1997, and the last one in the summer of 1998. As a result, the WDR was finished in all the areas by the spring of 1999. The first self-administered food frequency questionnaire (FFQ1) was carried out 2 weeks before the first WDR, and the second FFQ (FFQ2) took place 3 months after the fourth WDR. The interval between FFQs 1 \&2 was one year.

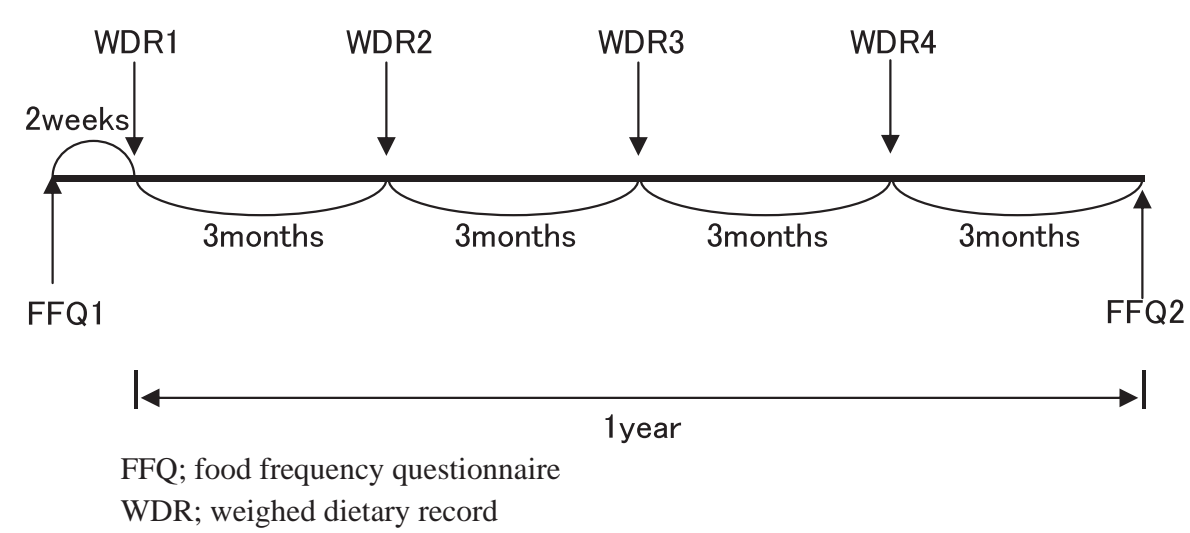

Figure1. Research design of JACC Study food frequency questionnaire validation study. 
Because this is a multi-center research study, the standardization of the method was necessary. Therefore, those in charge of the dietary survey in every group met together before the research started to receive detailed instructions about the data coding system and the research procedures. Because both food and cooking names were given in the food item section in the questionnaire, we decided to code both of them in order to compute nutrient contents, recipe by recipe.

The subjects were provided with a digital cooking scale (TANITA No. 1141, Tokyo). After the research, the cooking scales were given to them as a token of our appreciation of their cooperation.

\section{Data Collection}

When the WDR was finished for each season, the person in charge of the dietary survey collected the recording sheets from WDR. Each group's dietitian codified food items and food weights. Those data were mailed out to the dietary survey center in Osaka, where the dietitian in the dietary survey center checked the contents of the input data. If she found something ambiguous or unprocessed, she contacted the person in charge for clarification, thus completing the processing of the appropriate data. The self-administered FFQs 1 \& 2 were sent to Nagoya, the center of the JACC Study. After they were processed at Nagoya University, the FFQ data were mailed to the dietary survey center.

\section{Computation of Nutrient Intakes from WDR}

Based on the Standard Tables of Food Composition in Japan fourth revised edition, ${ }^{4}$ and the fatty acid composition table of Japanese food, ${ }^{5}$ we calculated the amounts of energy, protein (animal and vegetable), fat (animal, vegetable and fish), iron, calcium, potassium, salt, vitamin $\mathrm{A}$, vitamin $\mathrm{B}_{1}$, vitamin $\mathrm{B}_{2}$, vitamin $\mathrm{C}$, total fatty acid, saturated fatty acid (SFA), monounsaturated fatty acid (MUFA), polyunsaturated fatty acid (PUFA), and cholesterol. However, since the table has no entries for individual fatty acid components, we obtained a fatty acid composition database from Nagoya City University (Professor S. Tokudome) ${ }^{6}$ and from the National Cancer Center Research Institute East (Dr. S. Sasaki).

\section{Computation of Nutrient Intakes from FFQ}

The content of FFQs used in the research are as follows: the number of bowls of steamed rice consumed daily at baseline; the intake frequency of miso soup; and the number of bowls a day at baseline; questions about the intake frequency of 33 kinds of food items, with 5 multiple choice responses: almost never; $1-2$ times a month; 1-2 times a week; 3-4 times a week; almost everyday. There were other questions about the drinking habits of alcoholic beverages and soft drinks: coffee, black tea, Japanese green tea and Chinese tea. The questionnaires used in this study are shown in Appendix1 and Appendix2.

Each frequency weight was set at $0,0.05$ (1.5/30), 0.214 $(1.5 / 7)$, and $0.5(3.5 / 7)$, with 1.0 signifying the response 'almost everyday'. As for the frequency of miso soup, we set the four fre- quency weights, (i.e., every day; every other day; several times a month; seldom) as 1.0, 0.5, 0.1, and 0 , respectively.

With respect to the intake amount of consumed steamed rice, replies were made in terms of the number of medium-sized bowls consumed. Hence, one such bowl was estimated to contain $140 \mathrm{~g}$. The amount was thus obtained by multiplying $140 \mathrm{~g}$ by the number of bowls. The nutrient value of steamed rice is based on the Standard Tables of Food Composition in Japan, 4th revised edition. ${ }^{4}$

As for other foods, there were no questions about portion sizes in the questionnaires. However, we estimated them from the WDR results. That is, we computed the daily amount of food eaten by each person, based on the data from WDR, and determined the median as portion sizes (Table 1). As for food items without any specification, we decided on their nutrient composition as follows: there was no mention of the kinds of beef (e.g., sirloin, fillet) in the questionnaire, although various parts of beef were referred to in WDR. We selected them and computed those weighted mean ingredient values, based on the Standard Tables of Food Composition in Japan, 4th revised edition. ${ }^{4}$ The nutrient composition of foods other than beef was calculated in the same way.

As for butter and margarine, we calculated the median portion size by the same method as mentioned above. In Japan, few people use butter or margarine for cooking. Instead, they spread it on toast. We calculated the median portion size of bread, which turned out be $60 \mathrm{~g}$. We added its nutrient value to the nutritive composition of butter and margarine.

When any particular item was used as a recipe in the questionnaire (such as deep fried foods or tempura, fried vegetables, pickles, preserved foods using soy sauce, boiled beans, etc.), we computed the median daily amount of cooking based on WDR by selecting the code in the names. The nutrient composition value was computed, based on the weighted mean value of all foods used for such cooking.

We calculated the intake amount of coffee, black tea, Japanese green tea and Chinese tea by multiplying $100 \mathrm{~g}$ per cup by the number of cups. For their nutrient values, we used the coffee infusion, black tea infusion, coarse-grade Japanese tea infusion and oolong tea infusion as listed in the Standard Tables of Food Composition in Japan, 4th revised edition. ${ }^{4}$ In the questions regarding coffee and black tea, if sugar and milk were taken for drinking either beverage, we added $4 \mathrm{~g}$ for the sugar, $50 \mathrm{~g}$ for the milk and $2.5 \mathrm{~g}$ for substitute cream, each of which is the median amount used per cup in WDR. Then we calculated the sum of the products of the frequency weight and the nutrient content of the portion size for each food as the daily nutrient intake.

\section{Data Analysis}

We tested the reproducibility of intake frequency from FFQs 1 \& 2 and the amounts of the various nutrients calculated from FFQs 1 $\& 2$ by the Spearman rank correlation coefficient between the two FFQs, which were carried out twice at the interval of one year. 
In order to test the validity of the intake frequency of FFQ2, we defined the gold standard of intake frequency based on WDR as follows. First, corresponding to the frequency category of FFQ (almost never; 1-2 times a month; 1-2 times a week; 3-4 times a week; almost every day), we classified the frequency of 12-days WDR into five categories: never; 1 to 2 days; 3-5 days; 6-11 days; 12 days. Next, we counted the number of days during which the subjects ate each of the 33 food items, steamed rice, miso soup and beverages during the 12-day WDR and thereby determined the corresponding frequency categories. Then, we computed the Spearman rank correlation coefficients of 5 category classifications of the WDR and the FFQ2.

In order to examine the validity of the amount of nutrient intake computed from FFQ2 as mentioned above, we computed the
Spearman correlation coefficients (both crude correlation coefficients, and energy adjusted correlation coefficients ${ }^{9}$ ) between the WDR and the FFQ2.

We used the software package (SPSS ${ }^{\circledR} 11.5 \mathrm{~J}$ for Windows, SPSS Inc.) for computation.

\section{RESULTS}

\section{Analysis Subjects}

Though unfortunately nine participants dropped out of the research, the remaining 85 persons completed the two FFQs (FFQ1 \& FFQ2) and the 12-day WDR, and they were regarded as analysis subjects. Detailed information on them is shown in Table 2.
Table 1. Portion sizes for 33 food items.

\begin{tabular}{lc}
\hline \multicolumn{1}{c}{ Foods /Beverages } & portion size (g) \\
\hline Beef & 36 \\
Pork (excluding ham or sausage) & 41 \\
Ham or sausage & 22 \\
Chicken & 43 \\
Liver & 53 \\
Eggs & 37 \\
Milk & 146 \\
Yogurt & 98 \\
Cheese & 17 \\
Butter & 5 \\
Margarine & 6 \\
Deep-fried foods or tempura & 113 \\
Fried vegetables & 112 \\
Fresh fish & 63 \\
Kamaboko (fish paste) & 20 \\
Dried fish or salted fish & 29 \\
Spinach or garland chrysanthemum & 42 \\
Carrot or pumpkin & 23 \\
Tomatoes & 63 \\
Cabbage or head lettuce & 40 \\
Chinese cabbage & 66 \\
Edible wild plants & 36 \\
Fungi (enokidake, shiitake mushroom) & 17 \\
Potatoes & 52 \\
Algae (seaweeds) & 7 \\
Pickles & 26 \\
Preserved foods using soy sause & 10 \\
Boiled beans & 40 \\
Tofu (soybean curd) & 60 \\
Citrus fruits & 68 \\
Fresh fruits juice (in summer) & \\
Fruits (excluding citrus variety) & 38 \\
Sweets & \\
\hline
\end{tabular}

Table 2-1. The number of analysis subjects by group and sex.

\begin{tabular}{llcc}
\hline Group & Prefecture & Female & Male \\
\hline Yakumo Town & Hokkaido & 4 & 1 \\
Omori Town & Akita & 5 & 0 \\
Samukawa Town & Kanagawa & 5 & 0 \\
Higashi-Yamanashi County & Yamanashi & 10 & 0 \\
Shirakawa Town & Gifu & 5 & 0 \\
Gifu City & Gifu & 4 & 0 \\
Wachi Town & Kyoto & 5 & 0 \\
Wazuka Town & Kyoto & 7 & 0 \\
Keihoku Town & Kyoto & 5 & 0 \\
Ichinomiya Town & Hyogo & 10 & 0 \\
Saikawa Town & Fukuoka & 5 & 0 \\
Tokyo preventive medicine association & Tokyo & 3 & 6 \\
Personnel from Nagoya City government & Aichi & 4 & 1 \\
Dietitians from Nagoya City & Aichi & 5 & 0 \\
\hline Total & & 77 & 8 \\
\hline
\end{tabular}

Table 2-2. Age distribution of analysis subjects.

\begin{tabular}{lcr}
\hline Age(year) & Number & $\%$ \\
\hline $20-29$ & 1 & 1.2 \\
$30-39$ & 8 & 9.4 \\
$40-47$ & 25 & 29.4 \\
$50-59$ & 31 & 36.5 \\
$60-69$ & 19 & 22.4 \\
$70-79$ & 1 & 1.2 \\
\hline Total & 85 & 100 \\
\hline
\end{tabular}


Table 3. Spearman rank correlation coefficients between two frequencies (five categories) assessed with food frequency questionnaire administered twice apart one year. $(n=88)$

\begin{tabular}{|c|c|}
\hline Foods/Beverages & $\begin{array}{l}\text { arman correlation } \\
\text { coefficient }^{*}\end{array}$ \\
\hline Coffee & 0.86 \\
\hline Black tea & 0.74 \\
\hline Miso soup & 0.72 \\
\hline Liver & 0.71 \\
\hline Milk & 0.69 \\
\hline Pickles & 0.68 \\
\hline Ham or sausage & 0.67 \\
\hline Eggs & 0.66 \\
\hline Cabbage or head lettuce & 0.66 \\
\hline Algae (seaweeds) & 0.66 \\
\hline Tofu (soybean curd) & 0.64 \\
\hline Margarine & 0.63 \\
\hline Spinach or garland chrysanthemum & 0.63 \\
\hline Chinese cabbage & 0.63 \\
\hline Sweets & 0.62 \\
\hline Japanese green tea & 0.62 \\
\hline Steamed rice & 0.62 \\
\hline Potatoes & 0.61 \\
\hline Chinese tea & 0.61 \\
\hline Fungi (enokidake, shiitake mushroom) & 0.60 \\
\hline Beef & 0.59 \\
\hline Boiled beans & 0.59 \\
\hline Fruits (excluding citrus variety) & 0.58 \\
\hline Cheese & 0.57 \\
\hline Kamaboko (fish paste) & 0.57 \\
\hline Citrus fruits & 0.57 \\
\hline Preserved foods using soy sause & 0.56 \\
\hline Butter & 0.55 \\
\hline Fresh fruits juice(in summer) & 0.55 \\
\hline Yogurt & 0.54 \\
\hline Fresh fish & 0.54 \\
\hline Chicken & 0.53 \\
\hline Tomatoes & 0.53 \\
\hline Deep-fried foods or tempura & 0.52 \\
\hline Fried vegetables & 0.46 \\
\hline Dried fish or salted fish & 0.46 \\
\hline Pork (excluding ham or sausage) & 0.44 \\
\hline Carrot or pumpkin & 0.43 \\
\hline Edible wild plants & 0.42 \\
\hline Mean & 0.60 \\
\hline Median & 0.60 \\
\hline
\end{tabular}

* : If $\mathrm{r}=0.34$ then $\mathrm{p}=0.001 \quad(\mathrm{n}=85)$.
Table 4. Spearman rank correlation coefficients between two frequencies (five categories) assessed with 2nd food frequency questionnaire and weighed dietary record for 12 days. $(n=85)$

\begin{tabular}{|c|c|}
\hline Foods/Beverages & $\begin{array}{l}\text { arman correlation } \\
\text { coefficient }^{*}\end{array}$ \\
\hline Coffee & 0.81 \\
\hline Miso soup & 0.69 \\
\hline Milk & 0.65 \\
\hline Ham or sausage & 0.63 \\
\hline Steamed rice & 0.63 \\
\hline Margarine & 0.62 \\
\hline Black tea & 0.60 \\
\hline Yogurt & 0.58 \\
\hline Fungi (enokidake, shiitake mushroom) & 0.54 \\
\hline Butter & 0.51 \\
\hline Tofu (soybean curd) & 0.50 \\
\hline Beef & 0.49 \\
\hline Algae (seaweeds) & 0.46 \\
\hline Fresh fish & 0.45 \\
\hline Tomatoes & 0.45 \\
\hline Pickles & 0.45 \\
\hline Chicken & 0.44 \\
\hline Cheese & 0.44 \\
\hline Chinese tea & 0.43 \\
\hline Spinach or garland chrysanthemum & 0.42 \\
\hline Eggs & 0.40 \\
\hline Fruits (excluding citrus variety) & 0.39 \\
\hline Pork (excluding ham or sausage) & 0.37 \\
\hline Sweets & 0.36 \\
\hline Cabbage or head lettuce & 0.33 \\
\hline Carrot or pumpkin & 0.32 \\
\hline Boiled beans & 0.30 \\
\hline Citrus fruits & 0.26 \\
\hline Fresh fruits juice(in summer) & 0.24 \\
\hline Potatoes & 0.23 \\
\hline Japanese green tea & 0.21 \\
\hline Liver & 0.20 \\
\hline Chinese cabbage & 0.18 \\
\hline Deep-fried foods or tempura & 0.17 \\
\hline Dried fish or salted fish & 0.17 \\
\hline Preserved foods using soy sause & 0.16 \\
\hline Kamaboko (fish paste) & 0.12 \\
\hline Fried vegetables & 0.11 \\
\hline Edible wild plants & 0.07 \\
\hline Mean & 0.39 \\
\hline Median & 0.42 \\
\hline
\end{tabular}




Japanese green tea
\begin{tabular}{|l|c|c|c|c|c|}
\hline $\begin{array}{c}\text { WDR } \\
\text { 2nd } \\
\text { FFQ }\end{array}$ & never & $1-2$ days & $3-5$ days & $6-11$ days & 12 days \\
\hline $\begin{array}{l}\text { Almost } \\
\text { never }\end{array}$ & 1 & 0 & 0 & 2 & 3 \\
\hline $\begin{array}{l}1-2 \text { per } \\
\text { month }\end{array}$ & 1 & 1 & 0 & 0 & 1 \\
\hline $\begin{array}{l}1-2 \text { per } \\
\text { week }\end{array}$ & 0 & 0 & 1 & 0 & 1 \\
\hline $\begin{array}{l}3-4 \text { per } \\
\text { week }\end{array}$ & 0 & 0 & 0 & 3 & 1 \\
\hline $\begin{array}{l}\text { Almost } \\
\text { every day }\end{array}$ & 2 & 0 & 2 & 22 & 44 \\
\hline
\end{tabular}

$$
\begin{aligned}
& \text { Same category }=50 / 85 \\
& \text { Adjacent category }=74 / 85 \\
& \text { Reversal category }=5 / 85
\end{aligned}
$$

Same category $=$

Adjacent category $=$

Reversal category $=$

FFQ; food frequency questionnaire

WDR; weighed dietary record

\begin{tabular}{l} 
Liver \\
\begin{tabular}{|l|c|c|c|c|c|}
\hline $\begin{array}{l}\text { W DR } \\
\text { 2nd } \\
\text { FFQ }\end{array}$ & never & $1-2$ days & $3-5$ days & $6-11$ days & 12 days \\
\hline $\begin{array}{l}\text { Almost } \\
\text { never }\end{array}$ & 0 & 0 & 0 & 0 & 0 \\
\hline $\begin{array}{l}1-2 \text { per } \\
\text { month }\end{array}$ & 44 & 4 & & & \\
\hline $\begin{array}{l}1-2 \text { per } \\
\text { week }\end{array}$ & 25 & 7 & 0 & 0 & 0 \\
\hline $\begin{array}{l}3-4 \text { per } \\
\text { week }\end{array}$ & 3 & 1 & 0 & 0 & 0 \\
\hline $\begin{array}{l}\text { Almost } \\
\text { every day }\end{array}$ & 0 & 0 & 0 & 0 & 0 \\
\hline $\begin{array}{l}\text { Missing } \\
\text { data }\end{array}$ & 1 & & &
\end{tabular} \\
\hline
\end{tabular}

Same category $=4 / 84$

Adjacent category $=55 / 85$

Reversal category $=0 / 85$

Figure2. Contingency tables for joint classification intake frequency assessed by 2nd food frequency questionnaire and weighed dietary record for 12 days.

\section{Intake Frequency Assessment}

In Table 3, the Spearman rank correlation coefficients between FFQ1 \& FFQ2 are shown, in the order of height. Coffee had the highest correlation coefficient (0.86), whereas edible wild plants the lowest (0.42). The correlation coefficients for all the foods were found to be statistically significant, and the mean and the median of 39 food items were 0.60 .

In Table 4, the Spearman rank correlation coefficients between FFQ2 and 12-day WDR are shown, in the order of height. Coffee was found to have the highest $(0.81)$ correlation coefficient. while edible wild plants the lowest (0.07). This order was the same as that of reproducibility. The mean was 0.39 and the median was 0.42 . The foods whose correlation coefficients were not significant were deep-fried foods or tempura, preserved foods using soy sauce, kamaboko (fish paste), fried vegetables, and edible wild plants.

Figure 2 shows the relation between the frequency of Japanese green tea consumption and liver reported in the FFQ2, and their frequency evaluated in the 12-day WDR. We show the results by dividing them into three frames: the one where the frequency categories of the two methods corresponded, the one where the frequency categories are adjacent to each other, and the one where the frequency categories were in reversely results.
Table 5 shows the percentages classified into the same category according to the two methods shown in Figure 2, the percentage classified into the same category and the contiguity category, and the percentage classified into the reversely categories, in the descending order within the same category. The mean percentage of those classified into the same category was $36 \%$. Japanese green tea (59\%) was the highest, whereas liver (any kinds) (5\%) was the lowest. The classifications into reversely categories were found to exist in Japanese green tea (6\%), Chinese tea (2\%), milk, cheese, tofu, sweets, Chinese cabbage, and boiled beans (1\%).

\section{Nutrient Intake Assessment}

Table 6 shows mean total energy and 11 nutrients intakes assessed with WDR and FFQ. Also, Table 7 shows the amount of fatty acid intake assessed with WDR and FFQ. The intake amount of energy and nutrients assessed with FFQ was lower than with WDR. The percentage difference $\{(\mathrm{FFQ}-\mathrm{WDR}) / \mathrm{WDR}\}$ changed between $-64 \%$ of salt and $-15 \%$ of vitamin $A$. The mean percentage difference was $-37 \%$ and, the median was $36 \%$ among nutrients.

Table 8 shows the Spearman correlation coefficients between WDR and FFQ. We calculated 2 kinds of coefficients, using crude nutrient intakes and energy adjusted nutrient intakes by the 
Table 5. Comparison of 2 nd food frequency questionnaire with weighed dietary record for 12 days for frequency on joint classification by five categories. (\%)

\begin{tabular}{|c|c|c|c|}
\hline Foods /Beverages & Same category & Adjacent category & Reversal category \\
\hline Japanese green tea & 59 & 87 & 6 \\
\hline Chinese tea & 57 & 84 & 2 \\
\hline Milk & 48 & 87 & 1 \\
\hline Black tea & 48 & 84 & 0 \\
\hline Chicken & 47 & 95 & 0 \\
\hline Beef & 45 & 96 & 0 \\
\hline Pork (excluding ham or sausage) & 44 & 98 & 0 \\
\hline Butter & 43 & 85 & 0 \\
\hline Margarine & 43 & 81 & 0 \\
\hline Carrot or pumpkin & 42 & 92 & 0 \\
\hline Algae (seaweeds) & 40 & 94 & 0 \\
\hline Coffee & 40 & 80 & 0 \\
\hline Fried vegetables & 40 & 76 & 0 \\
\hline Fresh fish & 39 & 93 & 0 \\
\hline Cheese & 38 & 86 & 1 \\
\hline Eggs & 37 & 95 & 0 \\
\hline Cabbage or head lettuce & 37 & 90 & 0 \\
\hline Ham or sausage & 37 & 88 & 0 \\
\hline Tofu (soybean curd) & 36 & 90 & 1 \\
\hline Fungi (enokidake, shiitake mushroom) & 35 & 93 & 0 \\
\hline Kamaboko (fish paste) & 35 & 83 & 0 \\
\hline Pickles & 34 & 82 & 0 \\
\hline Deep-fried foods or tempura & 34 & 81 & 0 \\
\hline Preserved foods using soy sause & 33 & 73 & 0 \\
\hline Fruits (excluding citrus variety) & 32 & 90 & 0 \\
\hline Sweets & 30 & 80 & 1 \\
\hline Dried fish or salted fish & 30 & 79 & 0 \\
\hline Citrus fruits & 30 & 76 & 0 \\
\hline Fresh fruits juice (in summer) & 29 & 60 & 0 \\
\hline Spinach or garland chrysanthemum & 27 & 86 & 0 \\
\hline Tomatoes & 27 & 82 & 0 \\
\hline Chinese cabbage & 27 & 72 & 1 \\
\hline Potatoes & 26 & 88 & 0 \\
\hline Yogurt & 24 & 70 & 0 \\
\hline Boiled beans & 24 & 66 & 1 \\
\hline Edible wild plants & 17 & 58 & 0 \\
\hline Liver & 5 & 65 & 0 \\
\hline Mean & 36 & 83 & \\
\hline Median & 36 & 84 & \\
\hline
\end{tabular}


Table 6. Energy and nutrient intakes assessed with weighed dietary record (WDR) for 12-days and food frequency questionnaire (FFQ).

\begin{tabular}{|c|c|c|c|c|c|c|c|c|c|c|}
\hline \multirow{2}{*}{$\begin{array}{l}(\mathrm{n}=85) \\
\text { Nutrient }\end{array}$} & \multirow[b]{2}{*}{ unit } & \multicolumn{4}{|c|}{ Weighed dietary record (WDR) for 12-days } & \multicolumn{4}{|c|}{ Food frequency questionnaire (FFQ) } & \multirow[b]{2}{*}{ difference $^{\dagger}$} \\
\hline & & Mean \pm & SD & Median & $(25 \%, 75 \%)^{*}$ & Mean \pm & SD & Median & $(25 \%, 75 \%)^{*}$ & \\
\hline Energy & kcal/day & $1792 \pm$ & 285 & 1722 & $(1593,1996)$ & $1193 \pm$ & 234 & 1201 & $(1038,1366)$ & -33 \\
\hline Total protein Crude & g/day & $75.3 \pm$ & 13.0 & 76.0 & $(67.1,82.4)$ & $48.1 \pm$ & 13.0 & 46.7 & $(38.0,56.2)$ & -36 \\
\hline Energy adjusted & & $75.3 \pm$ & 7.4 & 75.1 & $(70.1,79.3)$ & $48.1 \pm$ & 6.6 & 48.5 & $(44.7,51.6)$ & -36 \\
\hline Animal proteinCrude & g/day & $40.9 \pm$ & 10.4 & 41.3 & $(34.1,46.7)$ & $25.7 \pm$ & 9.6 & 25.6 & $(17.6,32.3)$ & -37 \\
\hline Energy adjusted & & $40.9 \pm$ & 7.7 & 40.7 & $(36.4,46.2)$ & $25.7 \pm$ & 6.7 & 26.4 & $(22.6,29.2)$ & -37 \\
\hline Total fat & g/day & $53.2 \pm$ & 12.0 & 52.8 & $(45.9,60.7)$ & $29.6 \pm$ & 9.0 & 28.6 & $(23.5,34.8)$ & -44 \\
\hline Energy adjusted & & $53.2 \pm$ & 6.8 & 53.6 & $(49.0,57.4)$ & $29.6 \pm$ & 5.2 & 29.5 & $(26.6,32.9)$ & -44 \\
\hline Animal fat Crude & g/day & $20.8 \pm$ & 7.2 & 19.9 & $(15.4,25.4)$ & $14.5 \pm$ & 5.5 & 14.8 & $(10.4,18.0)$ & -30 \\
\hline Energy adjusted & & $20.8 \pm$ & 5.6 & 20.3 & $(16.6,25.1)$ & $14.5 \pm$ & 3.9 & 14.9 & $(11.6,16.9)$ & -30 \\
\hline Vegetable fatCrude & g/day & $26.3 \pm$ & 6.6 & 25.7 & $(22.4,29.8)$ & $11.7 \pm$ & 3.5 & 11.5 & $(9.3,14.0)$ & -56 \\
\hline Energy adjusted & & $26.4 \pm$ & 5.4 & 26.9 & $(23.5,29.9)$ & $11.7 \pm$ & 2.4 & 11.9 & $(10.7,13.0)$ & -56 \\
\hline Fish fat $\quad$ Crude & g/day & $6.0 \pm$ & 3.1 & 5.9 & $(3.7,7.6)$ & $3.4 \pm$ & 3.0 & 3.0 & $(1.8,4.8)$ & -43 \\
\hline Energy adjusted & & $6.0 \pm$ & 2.8 & 6.3 & $(4.3,8.2)$ & $3.4 \pm$ & 1.8 & 3.6 & $(2.3,4.89)$ & -43 \\
\hline Crude & $\mathrm{mg} /$ day & $11.3 \pm$ & 2.2 & 11.2 & $(9.5,12.8)$ & $7.0 \pm$ & 2.1 & 6.4 & $(5.4,8.4)$ & -38 \\
\hline Energy adjusted & & $11.3 \pm$ & 1.9 & 11.2 & $(9.8,12.7)$ & $7.0 \pm$ & 1.4 & 6.9 & $(6.1,7.9)$ & -38 \\
\hline Calcium & $\mathrm{mg} /$ day & $663 \pm$ & 191 & 632 & $(542,745)$ & $496 \pm$ & 151 & 485 & $(391,602)$ & -25 \\
\hline Energy adjusted & & $663 \pm$ & 171 & 642 & $(560,749)$ & $496 \pm$ & 100 & 512 & $(433,551)$ & -25 \\
\hline Potassium Crude & $\mathrm{mg} /$ day & $3000 \pm$ & 675 & 2983 & $(2433,3343)$ & $1939 \pm$ & 552 & 1948 & $(1529,2248)$ & -35 \\
\hline Energy adjusted & & $3000 \pm$ & 569 & 2881 & $(2632,3378)$ & $1939 \pm$ & 371 & 1996 & $(1719,2156)$ & -35 \\
\hline Crude & g/day & $10.9 \pm$ & 2.5 & 10.7 & $(9.2,12.0)$ & $4.0 \pm$ & 1.7 & 3.7 & $(2.9,4.6)$ & -64 \\
\hline Energy adjusted & & $10.9 \pm$ & 2.0 & 10.6 & $(9.4,11.7)$ & $4.0 \pm$ & 1.2 & 3.9 & $(3.4,4.6)$ & -64 \\
\hline Vitamin A Crude & IU/day & $2909 \pm$ & 1339 & 2583 & $(2040,3649)$ & $2477 \pm$ & 1400 & 2335 & $(1476,2939)$ & -15 \\
\hline Energy adjusted & & $2909 \pm$ & 1222 & 2616 & $(2154,3433)$ & $2477 \pm$ & 1271 & 2342 & $(1583,3107)$ & -15 \\
\hline Vitamin $B_{1} \quad$ Crude & $\mathrm{mg} /$ day & $1.08 \pm$ & 0.26 & 1.07 & $(0.88,1.21)$ & $0.71 \pm$ & 0.20 & 0.69 & $(0.54,0.85)$ & -35 \\
\hline Energy adjusted & & $1.08 \pm$ & 0.20 & 1.06 & $(0.95,1.15)$ & $0.71 \pm$ & 0.12 & 0.71 & $(0.64,0.76)$ & -35 \\
\hline Vitamin $B_{2} \quad$ Crude & $\mathrm{mg} /$ day & $1.53 \pm$ & 0.34 & 1.54 & $(1.30,1.76)$ & $1.05 \pm$ & 0.31 & 1.06 & $(0.82,1.28)$ & -31 \\
\hline Energy adjusted & & $1.53 \pm$ & 0.24 & 1.54 & $(1.37,1.69)$ & $1.05 \pm$ & 0.21 & 1.08 & $(0.96,1.17)$ & -31 \\
\hline Vitamin C Crude & $\mathrm{mg} /$ day & $138 \pm$ & 43 & 136 & $(108,165)$ & $96 \pm$ & 38 & 93 & $(68,121)$ & -30 \\
\hline Energy adjusted & & $138 \pm$ & 41 & 132 & $(106,158)$ & $96 \pm$ & 31 & 95 & $(76,118)$ & -30 \\
\hline Cholesterol Crude & $\mathrm{mg} /$ day & $378 \pm$ & 95 & 374 & $(323,443)$ & $228 \pm$ & 87 & 236 & $(153,297)$ & -40 \\
\hline Energy adjusted & & $378 \pm$ & 80 & 381 & $(329,418)$ & $228 \pm$ & 65 & 227 & $(181,276)$ & -40 \\
\hline
\end{tabular}

$*: 25$ and 75 percentiles.

$\dagger$ : (FFQ mean-WDR mean)/WDR mean $(\%)$ 
Table 7. Fatty acid intake assessed with weighed dietary record (WDR) for 12-days and food frequency questionnaire (FFQ).

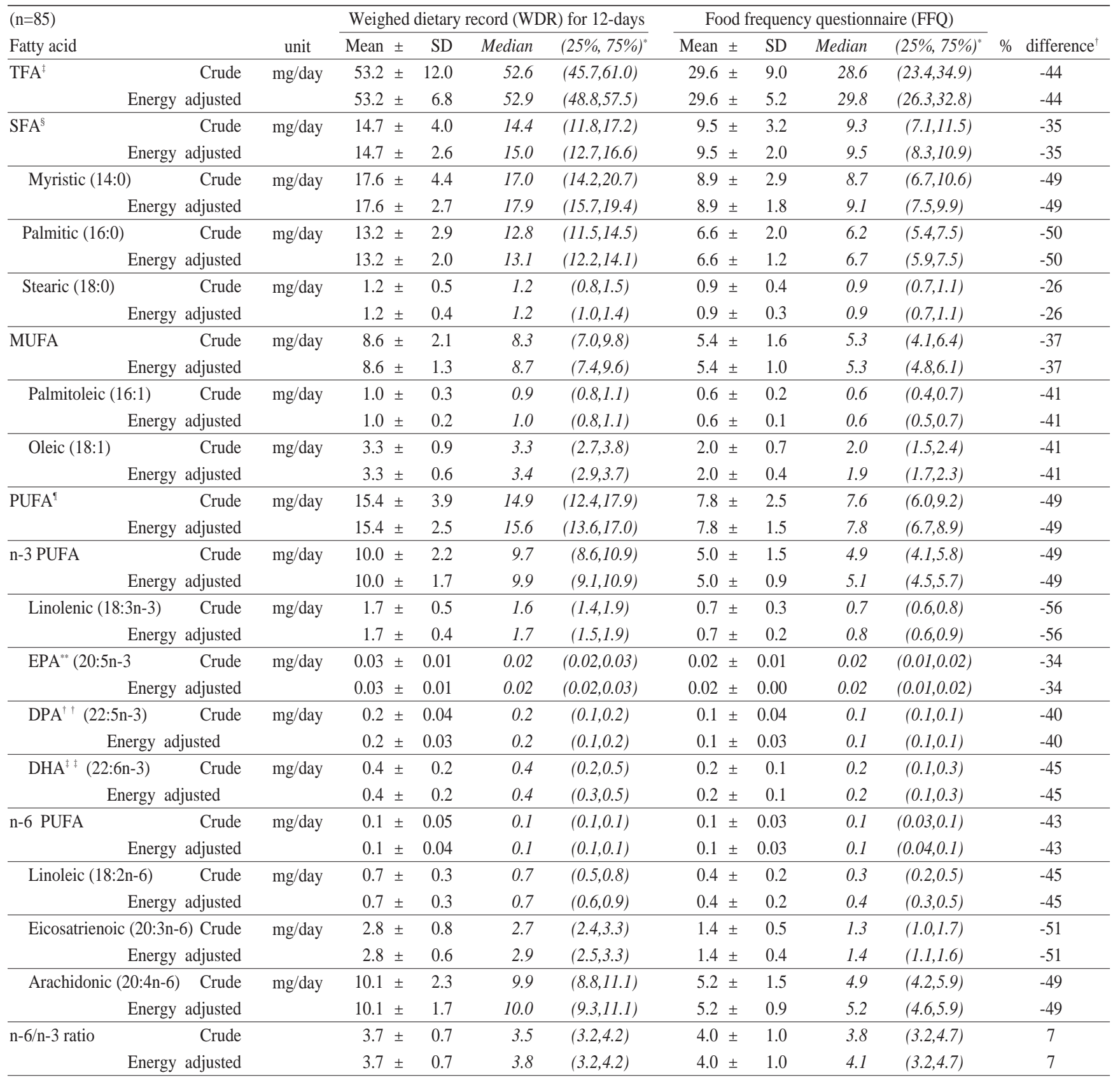

* : 25 and 75 percentiles.

$\dagger:$ (FFQ mean-WDR mean)/WDR mean $(\%)$

$\ddagger$ : Total fatty acids.

$\S:$ Saturated fatty acids.

$\|$ : Mono unsaturated fatty acids.

I : Poly unsaturated fatty acids.

**: Eicosapentaenoic acid.

$\dagger \dagger$ : Docosapentaenoic acids.

$\ddagger \ddagger$ : Docosahexaenoic acids. 
Table 8. Spearman correlation coefficients for energy and nutrient intakes between weighed dietary record for 12-days and food frequency questionnaire.

\begin{tabular}{|c|c|c|c|c|}
\hline \multirow{2}{*}{$\begin{array}{l}\mathrm{n}=85) \\
\text { Nutrient }\end{array}$} & \multicolumn{4}{|c|}{ Spearman correlation coefficients } \\
\hline & Crude & $\mathrm{p}$ value & Energy-adjusted & $\mathrm{p}$ value \\
\hline Energy & 0.20 & 0.065 & - & - \\
\hline Total protein & 0.24 & 0.027 & 0.24 & 0.025 \\
\hline Animal protein & 0.36 & 0.001 & 0.31 & 0.004 \\
\hline Total fat & 0.28 & 0.010 & 0.46 & 0.000 \\
\hline Animal fat & 0.46 & 0.000 & 0.51 & 0.000 \\
\hline Vegetable fat & 0.21 & 0.053 & 0.34 & 0.002 \\
\hline Fish fat & 0.28 & 0.008 & 0.21 & 0.049 \\
\hline Iron & 0.26 & 0.018 & 0.28 & 0.009 \\
\hline Calcium & 0.44 & 0.000 & 0.35 & 0.001 \\
\hline Potassium & 0.46 & 0.000 & 0.38 & 0.000 \\
\hline Salt & 0.35 & 0.001 & 0.31 & 0.004 \\
\hline Vitamin A & 0.28 & 0.009 & 0.35 & 0.001 \\
\hline Vitamin $\mathrm{B}_{1}$ & 0.33 & 0.002 & 0.36 & 0.001 \\
\hline Vitamin $B_{2}$ & 0.40 & 0.000 & 0.31 & 0.004 \\
\hline Vitamin C & 0.38 & 0.000 & 0.27 & 0.012 \\
\hline Cholesterol & 0.23 & 0.031 & 0.29 & 0.007 \\
\hline $\mathrm{TFA}^{*}$ & 0.26 & 0.018 & 0.39 & 0.000 \\
\hline $\mathrm{SFA}^{\dagger}$ & 0.36 & 0.001 & 0.50 & 0.000 \\
\hline Myristic (14:0) & 0.37 & 0.000 & 0.39 & 0.000 \\
\hline Palmitic (16:0) & 0.33 & 0.002 & 0.51 & 0.000 \\
\hline Stearic (18:0) & 0.33 & 0.002 & 0.47 & 0.000 \\
\hline MUFA $^{\ddagger}$ & 0.27 & 0.011 & 0.36 & 0.001 \\
\hline Palmitoleic (16:1) & 0.35 & 0.001 & 0.36 & 0.382 \\
\hline Oleic (18:1) & 0.26 & 0.016 & 0.41 & 0.369 \\
\hline PUFA $^{\S}$ & 0.20 & 0.070 & 0.15 & 0.183 \\
\hline n-3 PUFA & 0.25 & 0.019 & 0.21 & 0.058 \\
\hline Linolenic (18:3n-3) & 0.22 & 0.044 & 0.16 & 0.152 \\
\hline EPA $^{\|}(20: 5 n-3)$ & 0.26 & 0.015 & 0.19 & 0.089 \\
\hline DPA $^{\pi}(22: 5 n-3)$ & 0.27 & 0.012 & 0.23 & 0.033 \\
\hline $\operatorname{DHA}^{* *}(22: 6 n-3)$ & 0.24 & 0.024 & 0.19 & 0.075 \\
\hline n-6 PUFA & 0.17 & 0.119 & 0.16 & 0.143 \\
\hline Linoleic (18:2n-6) & 0.17 & 0.120 & 0.16 & 0.154 \\
\hline Eicosatrienoic (20:3n-6) & 0.40 & 0.000 & 0.44 & 0.000 \\
\hline Arachidonic (20:4n-6) & 0.28 & 0.011 & 0.24 & 0.027 \\
\hline n- $6 / n-3$ ratio & 0.24 & 0.025 & 0.24 & 0.029 \\
\hline Mean & 0.30 & & 0.31 & \\
\hline Median & 0.28 & & 0.31 & \\
\hline
\end{tabular}

* : Total fatty acids.

$\dagger$ : Saturated fatty acids.

$\ddagger$ : Mono unsaturated fatty acids.

$\S$ : Poly unsaturated fatty acids.

II : Eicosapentaenoic acid.

ๆ : Docosapentaenoic acids.

**: Docosahexaenoic acids. 
residual method. ${ }^{8}$ The Spearman correlation coefficient changed from 0.17 (linoleic acid) to 0.46 (animal fat, potassium), and the mean and median was 0.30 and 0.28 , respectively. When energy adjusted nutrient intakes were used, the Spearman coefficient ranged from 0.15 (PUFA) to 0.51 (animal fat). The mean and median was 0.33 and 0.35 , respectively.

In an epidemiologic study, researchers usually use evaluation by categorical classification rather than by the absolute value. We examined the validity of evaluating the amount of nutrient intakes by FFQ in four categories by quartiles. The percentage of coincidence (same category) varied between $45 \%$ (potassium) and $22 \%$ (MUFA). The mean coincidence percentage was $31 \%$ and the median was $33 \%$, and both the mean and median of the reversal category were $7 \%$, and varied between $2 \%$ (potassium) and $11 \%$ (energy).

\section{DISCUSSION}

In order to study the relation between chronic diseases and dietary factors, a researcher should investigate a subject's habitual dietary intake over a long period of time, rather than during a short term. The food frequency questionnaire method (FFQ) has been developed to show habitual dietary intake. ${ }^{2}$ If this method is used, it will, first of all, require a validity test to verify whether it is actually capable of showing an individual's habitual intake condition. A gold standard will be required for its validity test. We adopted the weighed dietary recording method (WDR) as the gold standard. The subjects recorded their dietary intake for 3 days every three months, totally 12 days in one year. In doing so, we took into consideration both their day-to-day variation and seasonal variation in dietary intake. Strictly speaking, subjects participating in the validity research should be chosen at random from cohort members belonging to the JACC Study. However, since WDR would be a considerable burden in terms of time and otherwise, we had to depend on volunteer members who understood the main objective of the research. Hence, the research results may not necessarily reflect the whole picture of the JACC members.

Because JACC Study was a large-scale cohort study involving more than 110,000 people, a self-administered food frequency questionnaire was used. Because the main purpose of the JACC Study was to clarify the risk factors of cancer, the questionnaire covered various areas, part of which contained questions about dietary intake. The questions were simple, mostly concerning intake frequency of a small number of food items, not their portion sizes. Second, because the focus of the questionnaire was on the kinds of food which had been considered to be the risk factors of cancer in the previous studies, ${ }^{9}$ we failed to evaluate the comprehensive situation regarding nutrient intake. Third, although there are ordinarily 100-150 food items are needed to evaluate the amount of nutrient intake comprehensively ${ }^{2}$, the research this time had only 40 items.

Considering the limited nature of the questionnaire above, we first examined the reproducibility and validity of intake frequency in detail, because frequency has a great influence on assessing the amount of nutrient intakes gained from FFQ. ${ }^{2}$ The mean of the percentage classified into the same category was $36 \%$, in which the intake frequencies assessed from WDR and FFQ. When the adjoining category was included, the mean value of the percentage of coincidence was $83 \%$. In classifying the subjects according to intake frequency, it was shown clearly, making allowance for the misclassification by the adjoining category, that most of the food items were suitable for making the category evaluation of the subjects correctly.

Although the percentage in which Japanese green tea can be classified into the same category was the highest, that of reversal misclassification was the highest as $6 \%$ (5 subjects as shown in Figure 2). Two subjects out of the five subjects were classified as "never drinking" in WDR, whereas it is classified as "drink almost every day" in FFQ. The reason this discrepancy occurred was obviously that some of those who were drinking barley tea (mugicha) in WDR, could not make a distinction between barley tea and Japanese green tea in the FFQ, and so they chose the latter beverage, thus making the percentage of green tea higher than it really was.

The percentage of coincidence of liver (any kinds) in the same category was the lowest. We thought that this was probably because most of the subjects were estimated as "never" in the category assessed by 12-day WDR, in view of the fact that people rarely eat liver daily. Even if a classification also included the adjoining category, the percentage of coincidence of the frequency between WDR and FFQ was the lowest.

As mentioned above, except for special foods, we considered the validity of intake frequency good. As for reproducibility, the correlation coefficient with the range of $0.42-0.80$ was shown by this study.

We already explained that FFQ examined in this study did not show the comprehensive amount of nutrient intake because the number of question items was 40 . The daily amount of energy and nutrient intake from FFQ were lower in all than those from WDR. When the difference of the amount of intake between FFQ and WDR was showed in terms of its proportion to the amount of intake from WDR, the smallest value was 15 (vitamin A) whereas the largest value was 64 (salt). We considered that the reason the difference in vitamin A was smaller than that of the other nutrients was probably because the FFQ contained three items of green and yellow vegetables, which reflect their important role as a source of vitamin A. The FFQ did not contain any seasonings as food items. According to the national nutrition survey in Japan ${ }^{10}$, Japanese people obtain about $70 \%$ of the daily salt intake from soy sauce, miso and such seasonings. All this explains why the difference in the amount of salt intake between FFQ and WDR was very large. Also, it is usually very difficult to evaluate the amount of seasoning intake from a FFQ., ${ }^{2,11}$

Tsugane and others made a detailed validity research of 138item semi quantitative food frequency questionnaire used in Japan 
Public Health Center-based Prospective Study on Cancer and Cardiovascular Diseases (JPCH Study), and published a series of papers on their research results. ${ }^{12}$ The JPCH Study was a cohort study targeted at residents of the areas under the jurisdiction of 4 public health centers in Akita Prefecture, Iwate Prefecture, Nagano Prefecture, and Okinawa Prefecture. They chose subjects for the validity study from cohort members as volunteers. For the gold standard, they used 7-day semi-weighed dietary records four times a year (winter, spring, summer and autumn, and a total of 28 days) or 7-day dietary records two times a year (winter and spring and a total of 14 days). Sasaki obtained 102 men and 113 women as subjects and made a report about them by the sex.

Our research method was different from the JPCH validation study in that our dietary records as the gold standard were shorter and that our FFQ had only 40 items. However, our research design was similar to theirs in using the Standard Tables of Food Composition in Japan, 4 th revised edition ${ }^{4}$ in computing nutrients. Because most of the targeted subjects were females in our study, we compared them with those in the JPCH Study. The JPCH classification was made into 5 categories by quintile, while ours was in 4 categories by quartile. The JPCH Study, which used 138 items in their FFQ, was capable of evaluating dietary intakes comprehensively. On the other hand, the correlation coefficients and analysis based on joint classification in the JACC Study were slightly lower than those of the JPCH Study. In determining portion sizes of food items, we adopted the median values of WDR, rather than general standard numerical values. This might have somehow raised the correlation coefficients between FFQ and WDR.

In conclusion, we found our FFQ suitable to deal with a large group of subjects. However, since the energy and the amount of nutrient intake from this FFQ can not show the comprehensive situation of dietary intake, subjects' dietary intake should be assessed by categories.

\section{MEMBER LIST OF THE JACC STUDY GROUP}

The present investigators involved, with the co-authorship of this paper, in the JACC Study and their affiliations are as follows: Dr. Akiko Tamakoshi (present chairman of the study group), Nagoya University Graduate School of Medicine; Dr. Mitsuru Mori, Sapporo Medical University School of Medicine; Dr. Yutaka Motohashi, Akita University School of Medicine; Dr. Ichiro Tsuji, Tohoku University Graduate School of Medicine; Dr. Yosikazu Nakamura, Jichi Medical School; Dr. Hiroyasu Iso, Institute of Community Medicine, University of Tsukuba; Dr. Haruo Mikami, Chiba Cancer Center; Dr. Yutaka Inaba, Juntendo University School of Medicine; Dr. Yoshiharu Hoshiyama, Showa University School of Medicine; Dr. Hiroshi Suzuki, Niigata University School of Medicine; Dr. Hiroyuki Shimizu, Gifu University School of Medicine; Dr. Hideaki Toyoshima, Nagoya University Graduate School of Medicine; Dr. Shinkan Tokudome, Nagoya City University Graduate School of Medical
Science; Dr. Yoshinori Ito, Fujita Health University School of Health Sciences; Dr. Shuji Hashimoto, Fujita Health University School of Medicine; Dr. Shogo Kikuchi, Aichi Medical University School of Medicine; Dr. Akio Koizumi, Graduate School of Medicine and Faculty of Medicine, Kyoto University; Dr. Takashi Kawamura, Kyoto University Center for Student Health; Dr. Yoshiyuki Watanabe, Kyoto Prefectural University of Medicine Graduate School of Medical Science; Dr. Tsuneharu Miki, Kyoto Prefectural University of Medicine Graduate School of Medical Science; Dr. Chigusa Date, Faculty of Human Environmental Sciences, Mukogawa Women's University ; Dr. Kiyomi Sakata, Wakayama Medical University; Dr. Takayuki Nose, Tottori University Faculty of Medicine; Dr. Norihiko Hayakawa, Research Institute for Radiation Biology and Medicine, Hiroshima University; Dr. Takesumi Yoshimura, Institute of Industrial Ecological Sciences, University of Occupational and Environmental Health, Japan; Dr. Akira Shibata, Kurume University School of Medicine; Dr. Naoyuki Okamoto, Kanagawa Cancer Center; Dr. Hideo Shio, Moriyama Municipal Hospital; Dr. Yoshiyuki Ohno, Asahi Rosai Hospital; Dr. Tomoyuki Kitagawa, Cancer Institute of the Japanese Foundation for Cancer Research; Dr. Toshio Kuroki, Gifu University; and Dr. Kazuo Tajima, Aichi Cancer Center Research Institute.

\section{ACKNOWLEDGMENTS}

The authors sincerely express their appreciation to Dr. Kunio Aoki, Professor Emeritus, Nagoya University School of Medicine and the former chairman of the JACC Study, and Dr. Haruo Sugano, the former Director, Cancer Institute, Tokyo, who greatly contributed to the initiation of the JACC Study, and Dr. Yoshiyuki Ohno, Professor Emeritus, Nagoya University School of Medicine, who was the past chairman of the study. The authors also wish to thank Dr. Tomoyuki Kitagawa, Cancer Institute of the Japanese Foundation for Cancer Research and the former chairman of Grant-in-Aid for Scientific Research on Priority Area 'Cancer', for his full support of this study. Also the authors express their great gratitude to Dr. Heizo Tanaka, the DirectorGeneral of the National Institute of Health and Nutrition, who planned this validation study and helped us to carry it out.

\section{REFERENCES}

1. Ohno Y, Tamakoshi A, JACC Study Group. Japan Collaborative Cohort Study for Evaluation of Cancer Risk Sponsored by Monbusho (JACC study). J Epidemiol, 2001; 11: $144-50$.

2. Willett W. Nutritional epidemiology. (2nd ed.) Oxford University Press, Oxford, 1998

3. Tsugane S, Sasaki S, Kobayashi M, Tsubono Y, Akabane M. Validity and reproducibility of the self-administered food frequency questionnaire in the JPHC Study Cohort I: study 
design, conduct and participant profiles. J Epidemiol, 2003; 13: S2-S12.

4. Science and Technology Agency. Standard Tables of Food Composition in Japan. The fourth revised edition. Printing Bureau. Ministry of Finance. Tokyo, 1982. (in Japanese)

5. Science and Technology Agency. Fatty acids, cholesterol, vitamin E composition table of Japanese foods. Ishiyaku Shuppan Publishers. Tokyo, 1990. (in Japanese)

6. Tokudome Y, Imaeda N, Ikeda M, Kitagawa I, Fujiwara N, Tokudome S. Foods contributing to absolute intake and variance in intake of fat, fatty acids and cholesterol in middleaged Japanese. J Epidemiol, 1999; 9: 78-90.

7. Sasaki S, Kobayashi M, Tsugane S. Development of substituted fatty acid food composition table for the use in nutritional epidemiologic studies for Japanese populations: its methodological backgrounds and the evaluation. J Epidemiol, 1999; 9: 190-207.

8. Willett W, Stampfer MJ. Total energy intake: Implications for epidemiologic analyses. Am J Epidemiol, 1986; 124:1727.
9. Committee on Diet, Nutrition, and Cancer. Diet, Nutrition, and Cancer. National Academy Press. Washington DC, 1982.

10. Office for Life-Style Related Diseases Control General Affairs Division, Health Service Bureau, Ministry of Health, Labour and Welfare, Japan. The National Nutrition Survey, Japan, 2001.

11. McKeown NM, Day NE, Welch AA, Runswick SA, Luben $\mathrm{RN}$, Mulligan AA, et al. Use of biological markers to validate self-reported dietary intake in a random sample of the European Prospective Investigation into Cancer United Kingdom Norfolk cohort. Am J Clin Nutr, 2001; 74: 188-96.

12. Tsugane S, Sasaki S, Kobayashi M, Ishihara J. Supplement to Journal of Epidemiology. Validity and reproducibility of self-administered food frequency questionnaires in the Japan Public Health Center-based Prospective Study on Cancer and Cardiovascular Diseases (JPHC Study). J Epidemiol, 2003; 13(Supplement) 
APPENDIX 1.

For each food listed, circle the number in the box indicating how often, you have used.

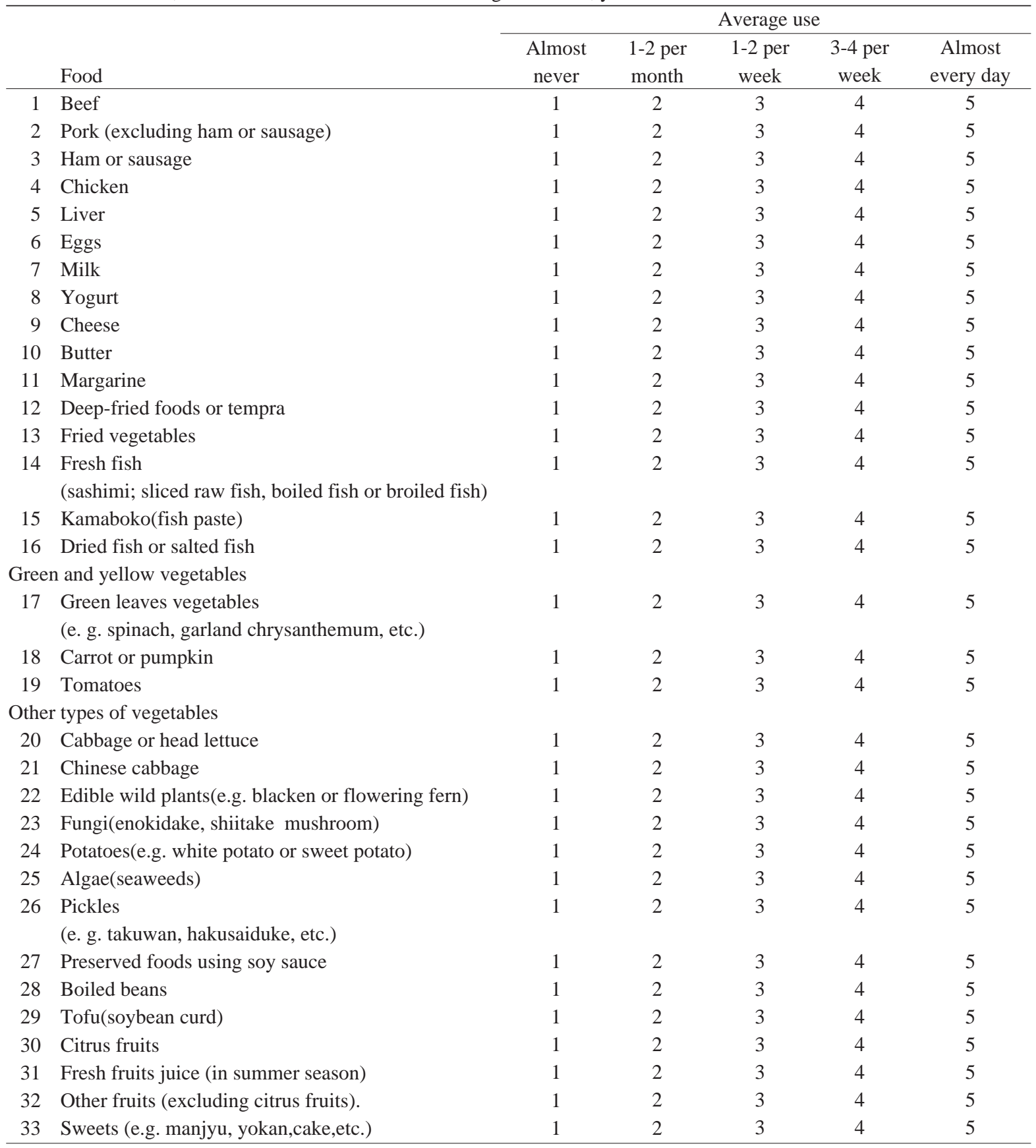




\section{APPENDIX 2}

For each food listed, circle the number indicating how often, you have used.

If you circle the number of every day or almost every day, write down appropriate number in the box

\section{Steamed rice}

How many bowls of steamed rice do you eat per day? bowls

\section{Miso soup}

1 every day

$\longrightarrow$ How many bowls of miso soup do you eat per day? $\square$ bowls

2 almost every other day

3 a few times per month

4 never

\section{Coffee}

1 almost every day

2 three or 4 caps per week

3 one or 2 caps per week

4 one or 2 caps per month

5 never

What kind of additives do you use with coffee?

1 sugar

2 artificial sweetener

3 milk

4 never

\section{Black tea}

1 almost every day $\longrightarrow \longrightarrow$ cups per day

2 three or 4 caps per week

3 one or 2 caps per week

4 one or 2 caps per month

5 never
1 sugar
2 artificial sweetener
3 milk
4 lemon
5 never

\section{Chinese tea}

1 almost every day

2 three or 4 caps per week

3 one or 2 caps per week

4 one or 2 caps per month

5 never

Alcoholic beverages

In the following section, please describe your drinking habit in the past year.

How often do you drink all kinds of alcoholic beverages?

1 almost every day(five or more days per week)

2 three or 4 days per week

3 one or 2 days per week

4 less than a day per week

5 never

What kind of alcoholic beverage do you drink?

1 Japanese Sake (fermented alcoholic beverage)

2 Shochu (distilled alcoholic beverage)

3 Beer

4 Whisky

5 Wine

How much do you drink per day?

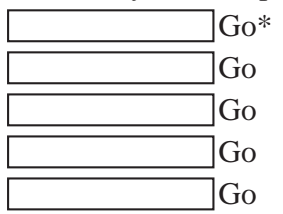

*:Go is a traditional measuring unit for Japanese Sake.

Japanese Sake contains alcohol $16 \%$ by volume. As one Go is $180 \mathrm{ml}$, one Go of Sake contains $29 \mathrm{~g}$ of alcohol.

Alcohol equivalents of various kinds of alcoholic beverages as mentioned above are as follows.
One large bottle of beer $=$ One Go
$180 \mathrm{ml}$ of Shochu $=$ One and half Go
Two fingers of whisky $=$ One Go
$180 \mathrm{ml}$ of wine $=$ One Go 